\title{
Oral cancer: The first symptoms and reasons for delaying correct diagnosis and appropriate treatment
}

\author{
Monika Rutkowska ${ }^{1, A-F}$, Sylwia Hnitecka ${ }^{2, A-F}$, Marek Nahajowski, ${ }^{3, A-F}$, Marzena Dominiakk ${ }^{4, E, F}$, Hanna Gerber ${ }^{5, B, E, F}$ \\ ${ }^{1}$ Clinical Department of Maxillofacial Surgery, $4^{\text {th }}$ Military Clinical Hospital, Wrocław, Poland \\ 2 Dental Clinic, $4^{\text {th }}$ Military Clinical Hospital, Wrocław, Poland \\ 3 Private dental practice, Wrocław, Poland \\ ${ }^{4}$ Department of Oral Surgery, Wroclaw Medical University, Poland \\ ${ }^{5}$ Department of Maxillofacial Surgery, Wroclaw Medical University Hospital, Poland \\ A - research concept and design; B - collection and/or assembly of data; $\mathrm{C}$ - data analysis and interpretation; \\ $D$ - writing the article; $E$ - critical revision of the article; $F$ - final approval of the article
}

\section{Address for correspondence \\ Sylwia Hnitecka \\ E-mail: sylwia.hnitecka@gmail.com}

Funding sources

None declared

Conflict of interest

None declared

Received on May 5, 2019

Reviewed on September 12, 2019

Accepted on January 21,2020

Published online on June 29, 2020

Cite as

Rutkowska M, Hnitecka S, Nahajowski M, Dominiak M, Gerber H. Oral cancer: The first symptoms and reasons for delaying correct diagnosis and appropriate treatment. Adv Clin Exp Med. 2020;29(6):735-743.

doi:10.17219/acem/116753

DOI

10.17219/acem/116753

Copyright

Copyright by Author(s)

This is an article distributed under the terms of the

Creative Commons Attribution 3.0 Unported (CC BY 3.0)

(https://creativecommons.org/licenses/by/3.0/)

\section{Abstract}

Background. The first symptoms of oral cancer are nonspecific. They raise suspicions of other, less serious conditions. Treatment of oral cancer is challenging, and the time of its detection and the implementation of appropriate therapy affect the prognosis.

Objectives. To identify predisposing factors, symptoms, time of, and reasons for delays in the diagnosis and appropriate treatment of oral cancer.

Material and methods. This retrospective analysis includes patients who were hospitalized with a diagnosis of carcinoma at the Clinical Department of Maxillofacial Surgery at the $4^{\text {th }}$ Military Clinical Hospital and Polyclinic in Wrocław, Poland, between 2008 and 2018, and at the Department of Maxillofacial Surgery at Wroclaw Medical University Hospital between 2010 and 2018. The analysis took into account the data obtained from the patients' medical records.

Results. This study comprised 305 patients (112 female; 36.7\% and 193 male; 63.3\%). The most frequent diagnosis was squamous cell carcinoma ( $N=294 ; 96.4 \%)$. The floor of the mouth was the most frequent primary site ( $N=103 ; 33.8 \%)$, followed by the anterior $2 / 3$ of the tongue $(N=94 ; 30.8 \%)$ and lower gingiva ( $N=43 ; 14.1 \%)$. A significant percentage were reported at an advanced stage (73.5\% in stages III and IV combined). The reasons for the late-stage diagnoses depended on the patients (40.6\%), the doctors (24.9\%) or both (10.8\%). Only $47.5 \%$ of patients reported because of the initial symptom noticed. Nearly half of the patients reported after 3-6 months of observing symptoms, usually to a general practitioner (GP; 35.7\%) or a dentist (31.8\%).

Conclusions. The oncological awareness of patients and healthcare professionals is an essential issue. Doctors often recommend inappropriate treatment, sometimes without monitoring its effectiveness. Dentists should consider cancer in the differentiation of clinical manifestations of other oral disorders.

Key words: oral diseases, head and neck cancer, oral cancer 


\section{Introduction}

Oral cancer is a significant public health problem, causing many deaths. According to the GLOBOCAN 2018 project, coordinated by the International Agency for Research on Cancer (IARC) of the World Health Organization, the estimated incidence of lip and oral cancer is 354,864 (2\%), and its estimated mortality is $177,384(1.9 \%) .{ }^{1}$ Over $90 \%$ of cancers in the head and neck region are head and neck squamous cell carcinomas (HNSCC). ${ }^{2}$ Oral cancer affects men more often, but the male-to-female ratio is decreasing. The risk of developing this disease is higher after the age of $45 .^{3}$ The five-year survival rate correlates with tumor advancement: The rate is about $80 \%$ for stage I cancer, and only around $20 \%$ for patients with stages III or IV. ${ }^{4}$ A significant percentage of patients report with cancer at an advanced stage, which often qualifies the patient for only palliative treatment. At the moment of diagnosis, regional metastases are present in about $40 \%$ of cases, and distant metastases in about 6\%, despite the accessibility of the oral cavity to examination even without specific diagnostic instruments. ${ }^{5,6}$

This has given rise to investigations of the causes of these significant diagnostic and therapeutic delays. Oncological awareness in society is crucial; it is the subject of many prohealth campaigns, aimed at drawing attention to the need for early cancer detection. This issue is not common in the literature - such state of affair emphasizes the need to pay more attention to this problem because early diagnosis of oral malignancy at an early stage may reduce death, morbidity and disfigurement from this disease. ${ }^{7}$

Insufficient oncological awareness and ignorance of the potential etiology (cancer) of symptoms are the most relevant aspects concerning the patients. Despite noticing a lesion, patients downplay it as long as it does not interfere with their functionality to a significant extent. Often patients report to the doctor only when pain occurs or, worse, or when they have difficulty in eating or speaking. ${ }^{8,9}$

The level of doctors' awareness also may require improvement. ${ }^{10,11}$ Most of the time, like patients, they do not associate the presented symptoms with neoplastic etiology. Poor diagnoses and a consequent lack of or correct initial therapy (i.e., long-term, ineffective antibiotic therapy or other pharmacotherapy, periodontal, surgical or endodontic treatment, prosthetic correction) result in significant delays in the appropriate treatment process. Such incorrect treatment may make patients' condition even worse. ${ }^{8,11}$ Besides dangerous delays and failures to continue further diagnosis, the recommended monitoring of the effectiveness of the initial treatment is often lacking.

Oral cancer influences the quality of life of patients because it impairs the efficiency of eating and speech. The esthetics of the oral region is also an important aspect. When the tumor is in an advanced stage, it results in the need for extensive surgery, which has a negative influence on both functionality and esthetics. ${ }^{6,11}$
The aim of the study was to determine the first symptoms of oral cancer, the reasons that prompt patients to selfreport to doctors and the reasons for delays in the appropriate diagnosis and treatment, depending on both healthcare professionals and patients. The $2^{\text {nd }}$ aim was to draw attention to the need to increase the level of oncological awareness in society at large and among healthcare professionals in particular.

\section{Material and methods}

The research material comprised patients hospitalized between 2008 and 2018 at the Clinical Department of Maxillofacial Surgery of the $4^{\text {th }}$ Military Clinical Hospital and Polyclinic in Wrocław (Poland), and between 2010 and 2018 at the Department of Maxillofacial Surgery of Wroclaw Medical University Hospital.

The analysis included patients with a pathological diagnosis of carcinoma and with tumors within the oral cavity. The analysis excluded patients with a pathological diagnosis other than carcinoma, patients hospitalized because of tumor recurrence or with a primary location other than the oral cavity (metastatic tumor), and patients with any missing data.

This retrospective analysis comprised data from the patients' medical records and pathological results. The data referred to the patients (their age at the time of diagnosis, concomitant systemic diseases, previous oncological therapy, malignancies in the family, addictions); the tumor (the pathological diagnosis, primary site, clinical tumor/ node/metastasis (TNM) staging and advancement (I-IV), macroscopic appearance); the diagnostic process and type of therapy before the patient's admission to the hospital (the time that passed from the first noticed symptom to the patient reporting to the ward, the nature of the first symptom, the sign that prompted the patient to self-report to a healthcare provider, the specialty of the first healthcare professional consulted, the first therapy (or other medical activity) implemented, the number of doctors consulted before admission to the ward); and the reasons for delays in implementing the appropriate diagnostic and therapeutic procedures, categorized as reasons that depended on the patients, those that depended on the doctors, or both.

The statistical analysis was carried out using STATISTICA v. 12 software (StatSoft, Inc., Tulsa, USA). The Kolmogorov-Smirnov and Shapiro-Wilk tests were used to check the compatibility of empirical distributions of quantitative traits with the theoretical normal distribution. The non-parametric Mann-Whitney U test verified the significance of differences in the values of average features with distributions different from normal or with heterogeneous variances in 2 independent groups. Pearson's $X^{2}$ test or Spearman's rank correlation coefficient verified the independence of 2 qualitative variables. 


\section{Results}

\section{Age, sex, addictions, systemic disorders, and past oncological therapy}

The analysis included 305 patients (112 female (F, 36.7\%) and 193 male (M, 63.3\%)). The mean age of the group was $60.7 \pm 10.3$ years (range: $22-87$ years); 14 patients ( $10 \mathrm{M}, 4 \mathrm{~F})$ were under 45 years of age. The women were older than the men by an average of 4.7 years, which was statistically significant $(\mathrm{p}<0.001)$. A predominance of males was found at a ratio of 1.7:1.

Among the patients, 248 (81.3\%) admitted smoking currently or in the past, 255 (83.6\%) reported drinking alcohol, 221 (72.5\%) consumed alcohol occasionally, and 34 (11.1\%) reported significant alcohol abuse. In 32 cases (10.5\%), smoking and significant alcohol abuse coexisted. The men used stimulants more often than women $(\mathrm{p}<0.001)$.

We found that 176 of the patients (57.7\%) suffered from concomitant systemic diseases such as cardiovascular diseases, diabetes, hypo/hyperthyroidism, or rheumatic diseases. Systemic diseases were more frequent in the older patients (over 60 years of age) than in those under $45(77.4 \%$ vs $39.6 \%, \mathrm{p}<0.001)$, while older people were less likely to use stimulants $(86.3 \%$ vs $94.3 \%, \mathrm{p}=0.017)$.

Investigating the patients' oncological history, we found that 32 of them (10.5\%) had undergone other oncological therapy in the past. There were malignancies in family members in 46 cases (15\%) (Table 1 ).

\section{Pathological results, location, clinical stage}

The floor of the mouth was the most frequent location $(\mathrm{N}=103 ; 33.8 \%)$, followed by the anterior $2 / 3$ of the tongue $(\mathrm{N}=94 ; 30.8 \%)$ and lower gingiva $(\mathrm{N}=43 ; 14.1 \%)$. The significant advancement of the tumor in 33 cases made it impossible to determine the primary site within the oral cavity. As for the pathological diagnosis, cases of squamous cell carcinoma were dominant $(\mathrm{N}=294 ; 96.4 \%)$, although there were also patients with a diagnosis of adenoid cystic
Table 1. Characteristics of the cases analyzed

\begin{tabular}{|c|c|c|}
\hline Clinical feature & \multicolumn{2}{|c|}{ Value } \\
\hline Mean age & \multicolumn{2}{|c|}{60.7} \\
\hline Range & \multicolumn{2}{|c|}{$22-87$} \\
\hline Age $<45$ & \multicolumn{2}{|c|}{$N=14$} \\
\hline Age $>45$ & \multicolumn{2}{|c|}{$N=291$} \\
\hline Sex ratio M:F & \multicolumn{2}{|c|}{$1.7: 1$} \\
\hline Addictions & $\mathrm{N}$ & $\%$ \\
\hline Smoking & 248 & 81.3 \\
\hline Drinking alcohol & 255 & 83.6 \\
\hline Diseases & $\mathrm{N}$ & $\%$ \\
\hline $\begin{array}{l}\text { Concomitant systemic diseases (e.g., } \\
\text { cardiovascular disease, diabetes, hypo-/ } \\
\text { hyperthyroidism, rheumatic diseases) }\end{array}$ & 176 & 57.7 \\
\hline Oncological history & $\mathrm{N}$ & $\%$ \\
\hline Previous oncological treatment & 32 & 10.5 \\
\hline Incidence of cancer in the family & 46 & 15.0 \\
\hline Primary cancer site & $\mathrm{N}$ & $\%$ \\
\hline Floor of the mouth & 103 & 33.8 \\
\hline Tongue - anterior $2 / 3$ & 94 & 30.8 \\
\hline Lower gingiva & 43 & 14.1 \\
\hline Impossible to determine the primary site & 33 & 10.8 \\
\hline Upper gingiva & 13 & 4.3 \\
\hline Buccal mucosa & 11 & 3.6 \\
\hline Hard palate & 8 & 2.6 \\
\hline
\end{tabular}

$\mathrm{N}$ - number of patients; $\mathrm{M}$ - male; F - female.

carcinoma $(\mathrm{N}=5 ; 1.6 \%)$, adenocarcinoma $(\mathrm{N}=4 ; 1.3 \%)$, lymphoepithelial carcinoma $(\mathrm{N}=1 ; 0.3 \%)$, and mucoepidermoid carcinoma $(\mathrm{N}=1 ; 0.3 \%)$. Table 1 shows the distribution of the primary tumor locations.

At the time of the patients' admission to the ward, 81 of them $(26.5 \%)$ were in the early stages of advancement (I: $\mathrm{N}=26, \mathrm{II}: \mathrm{N}=55)$ and $224(73.5 \%)$ in late stages (III: $\mathrm{N}=64, \mathrm{IV}: \mathrm{N}=160)$. Nodal metastases $(\mathrm{N}>0)$ existed in 193 cases $(63.3 \%)$, while distant metastases (M1) existed in 7 patients $(2.3 \%)$ (Table 2 ).

Table 2. Tumor stages, sex and age distribution of the population, time (counted in months) that passed between noticing the first symptom and the patient reported to the ward, and the number of doctors consulted

\begin{tabular}{|c|c|c|c|c|c|}
\hline \multirow{2}{*}{\multicolumn{2}{|c|}{ Variable }} & \multicolumn{4}{|c|}{ Tumor stage } \\
\hline & & 1 & II & III & IV \\
\hline \multirow{2}{*}{ Sex } & male, N (\% of male) & $15(7.8)$ & $21(10.9)$ & $41(21.2)$ & $116(60.1)$ \\
\hline & female, $\mathrm{N}$ (\% of female) & $11(9.8)$ & $34(30.4)$ & $23(20.5)$ & $44(39.3)$ \\
\hline \multirow{3}{*}{ Age } & $<45$ years, $\mathrm{N}$ (\% of patients < 45 years) & $1(7.1)$ & $2(14.35)$ & $5(35.7)$ & $6(42.85)$ \\
\hline & $45-69$ years, $N$ (\% of patients $45-69$ years) & $19(8.1)$ & $43(18.3)$ & $46(19.6)$ & $127(54)$ \\
\hline & $\geq 70, \mathrm{~N}$ (\% of patients $\geq 70$ years) & $6(10.7)$ & $10(17.9)$ & $13(23.2)$ & $27(48.2)$ \\
\hline \multicolumn{2}{|c|}{ Time [months], average } & $7.5 \pm 9.7$ & $9.1 \pm 24.2$ & $6.1 \pm 6.0$ & $7.25 \pm 11.7$ \\
\hline \multicolumn{2}{|c|}{ Number of doctors, average } & $1.6 \pm 0.9$ & $1.5 \pm 1$ & $1.75 \pm 1.2$ & $1.4 \pm 0.85$ \\
\hline
\end{tabular}

$\mathrm{N}$ - number of patients. 


\section{Total delay time}

The time (in months) that had passed from noticing the first symptom until the patient reported to the Department of Maxillofacial Surgery was on average $7.4 \pm 13.9$ months (min: 2 weeks, max: about 15 years). The time is given approximately because patients could not determine it accurately. There was no significant correlation between gender and delay time $(p>0.05)$ or between tumor advancement and delay time ( $\mathrm{p}>0.05)$ (Fig. 1). There was no correlation between tumor advancement (stage and metastases) and the presence of any factor delaying correct diagnosis and appropriate therapy $(\mathrm{p}>0.05)$ (Table 3), nor between tumor advancement and the time of patient's initial consultation with a doctor (i.e., when the patient reported to a doctor because of the first noticed symptom) ( $\mathrm{p}>0.05)$.

In some cases, the patient consulted a number of specialists. In this study, the patients most often consulted

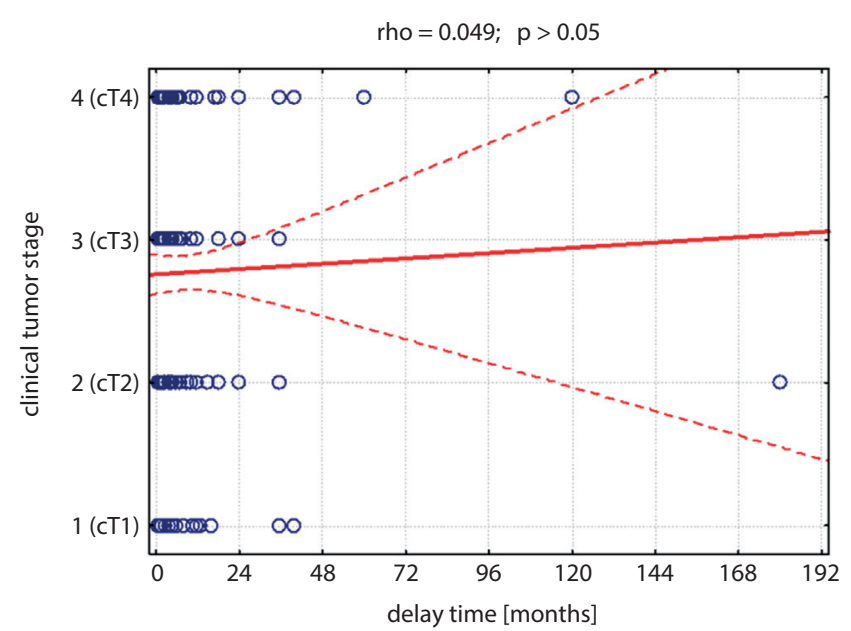

Fig. 1. Correlation diagram between the delay time and the stage of the tumor, with the value of Spearman's rank correlation coefficient (rho)

Table 3. The influence of delays in appropriate treatment on tumor advancement

\begin{tabular}{|c|c|c|c|}
\hline \multirow{2}{*}{$\begin{array}{c}\text { Tumor } \\
\text { advancement }\end{array}$} & \multicolumn{2}{|c|}{ Delay in appropriate treatment } & \multirow{2}{*}{$\begin{array}{c}\text { Test result } \\
\text { p-value }\end{array}$} \\
\hline & $\begin{array}{c}\text { no } \\
N=148\end{array}$ & $\begin{array}{c}\text { yes } \\
N=157\end{array}$ & \\
\hline CT1 & $20(13.5 \%)$ & $21(13.4 \%)$ & 0.572 \\
\hline CT2 & $42(28.4 \%)$ & $49(31.2 \%)$ & \\
\hline cT3 & $39(26.4 \%)$ & $31(19.8 \%)$ & \\
\hline CT4 & $47(31.8 \%)$ & $56(35.7 \%)$ & \\
\hline \multirow{2}{*}{ Metastasis } & \multicolumn{2}{|c|}{ Delay in appropriate treatment } & \multirow{2}{*}{$\begin{array}{l}\text { Test result } \\
\text { p-value }\end{array}$} \\
\hline & $\begin{array}{c}\text { no } \\
N=148\end{array}$ & $\begin{array}{c}\text { yes } \\
N=157\end{array}$ & \\
\hline M1 & $5(3.4 \%)$ & $2(1.3 \%)$ & 0.271 \\
\hline$M x$ & $143(96.6 \%)$ & & \\
\hline
\end{tabular}

$\mathrm{N}$ - number of patients; CT - clinical stage of tumor advancement.
1 healthcare professional $(\mathrm{N}=132 ; 43.2 \%)$ and slightly less often $2(\mathrm{~N}=88$; 28.8\%; min: 0 (patients who reported directly to the ward); max: 5 ; average: $1.5 \pm 1$; Table 2 ). There was no significant correlation between the tumor stage and the number of doctors consulted ( $\mathrm{p}>0.05$ ), but there was a weak positive correlation between the delay time and the number of doctors consulted before admission to the ward $(\mathrm{p}<0.05)$.

\section{Symptoms and other pathological lesions}

Ulceration was most frequent clinical appearance of a typical neoplastic lesion $(\mathrm{N}=176 ; 57.7 \%)$, followed by induration $(\mathrm{N}=135 ; 44.3 \%)$ and rupture $(\mathrm{N}=43 ; 14.1 \%)$. The lesion often manifested with symptoms of inflammation and bloody or purulent discharge. Sometimes it had even necrotic parts. Accompanying symptoms depended on the severity of the tumor; a significant correlation was found between increasing tumor advancement and an increasing number of accompanying symptoms ( $<<0.001$ ) (Fig. 2). Lockjaw was present in 9 cases $(3 \%)$, impaired tongue movement in 38 (12.5\%) and paresthesia of the mandibular nerve $\left(\mathrm{V}_{3}\right)$ in $14(4.6 \%)$. No significant correlation between the duration of the disease or location of the tumor and the number of additional symptoms was found ( $p>0.05$ ). There were also other pathological mucosal lesions within the oral cavity in 25 cases (8.2\%), including leukoplakia, dysplastic lesions, papillary or red hypertrophic lesions, lichen planus, or prosthetic stomatitis. A significant oral hygiene deficit was observed in 60 patients $(19.7 \%)$. A few patients $(\mathrm{N}=6 ; 2 \%)$ were suffering from mental disorders caused by their disease, while 21 (6.9\%) arrived at the ward in a state of cachexia. Palliative therapy was the only treatment option for 5 patients (1.6\%) because of the significant advancement of their cancer.

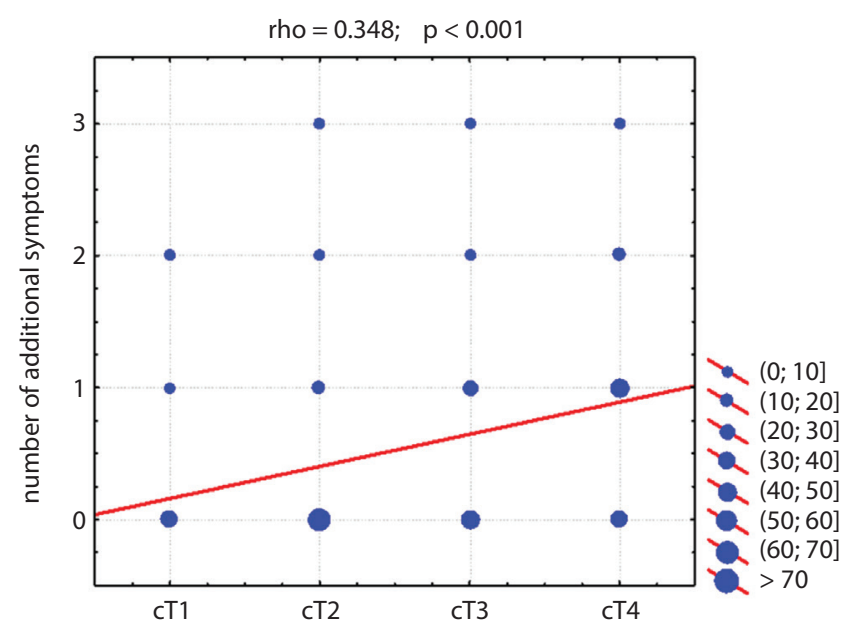

Fig. 2. Correlation diagram between tumor progression and the number of accompanying symptoms, with the value of Spearman's rank correlation coefficient (rho) 


\section{First consultations, reasons and first noticed symptoms}

The medical specialists to whom patients most often reported with their first noticed symptoms were established on the basis of interviews. General practitioners (GPs) were the first healthcare professional consulted most frequently $(\mathrm{N}=109 ; 35.7 \%)$, with dentists slightly less often $(\mathrm{N}=97$; 31.8\%) (Table 4).

The first symptoms that the patients noticed were also determined. Most often they observed an undefined lesion $(\mathrm{N}=90 ; 29.5 \%)$, ulceration $(\mathrm{N}=46 ; 15.1 \%)$ or induration $(\mathrm{N}=40 ; 13.1 \%)$ (Table 5$)$. The first symptom noticed by the patient (or sometimes incidentally detected by a doctor) prompted a visit to a doctor in only $47.5 \%$ of the cases, but there was no significant correlation between patients' early consultation with a doctor
Table 4. Specialist first visited

\begin{tabular}{|l|c|c|}
\hline \multicolumn{1}{|c|}{ Type of specialist } & N & $\%$ \\
\hline General practitioner & 109 & 35.7 \\
\hline Dentist & 97 & 31.8 \\
\hline Directly to the maxillofacial department & 48 & 15.7 \\
\hline Laryngologist & 45 & 14.8 \\
\hline Oncologist & 4 & 1.3 \\
\hline Dermatologist & 1 & 0.3 \\
\hline Endocrinologist & 1 & 0.3 \\
\hline
\end{tabular}

$\mathrm{N}$ - number of patients.

and tumor advancement $(\mathrm{p}>0.05)$. Often, patients sought medical help only at the time of the appearance of further symptoms or worsening of existing symptoms (Table 5).

Table 5. The nature of the first symptom noticed and of the symptom that prompted the patient to report to a doctor

\begin{tabular}{|c|c|c|c|c|c|}
\hline First noticed symptom & $\mathrm{N}$ & $\%$ & Symptom that prompted the patient to report to the doctor & $\mathrm{N}$ & $\%$ \\
\hline Lesion & 90 & 29.5 & first noticed symptom & 145 & 47.5 \\
\hline Ulceration & 46 & 15.1 & enlargement of the lesion & 51 & 16.7 \\
\hline Tumor & 40 & 13.1 & pain (appearance after time) & 38 & 12.5 \\
\hline Pain (tumor area) & 21 & 6.9 & intensification of symptoms that had been present for some time & 22 & 7.2 \\
\hline Dysphagia & 17 & 5.6 & accidental detection & 17 & 5.6 \\
\hline Wound/rupture & 13 & 4.3 & lack of healing/improvement after initial treatment implemented & 13 & 4.3 \\
\hline Unnoticed & 13 & 4.3 & check-up for another reason & 10 & 3.3 \\
\hline Sore throat & 12 & 3.9 & burning feeling & 5 & 1.6 \\
\hline White/grey spot & 11 & 3.6 & pain when swallowing & 5 & 1.6 \\
\hline Pain/burning/numbness & 8 & 2.6 & difficult speech & 4 & 1.3 \\
\hline Discomfort & 6 & 2 & tumor & 4 & 1.3 \\
\hline Tooth pain & 6 & 2 & tumor decay & 3 & 1 \\
\hline Hoarseness & 6 & 2 & ulceration & 2 & 0.7 \\
\hline Prosthesis mismatch & 5 & 1.6 & suppuration & 2 & 0.7 \\
\hline Neck lump & 4 & 1.3 & sudden mismatch of prosthesis & 2 & 0.7 \\
\hline Ulceration under a prosthesis & 4 & 1.3 & edema & 1 & 0.3 \\
\hline Protuberance & 4 & 1.3 & limitation of tongue mobility & 1 & 0.3 \\
\hline Face or neck pain & 4 & 1.3 & neck lump & 1 & 0.3 \\
\hline No healing of post-extraction socket & 4 & 1.3 & ear pain & 1 & 0.3 \\
\hline Edema & 4 & 1.3 & trismus & 1 & 0.3 \\
\hline Infiltration & 3 & 1 & & & \\
\hline Excrescence & 3 & 1 & & & \\
\hline Speech disorders & 2 & 0.7 & & & \\
\hline Cough & 2 & 0.7 & & & \\
\hline Pain under prosthesis & 2 & 0.7 & & & \\
\hline Gingival bleeding & 2 & 0.7 & & & \\
\hline Ear pain & 2 & 0.7 & & & \\
\hline Feeling an obstacle in the throat & 1 & 0.3 & & & \\
\hline Loss of smell & 1 & 0.3 & & & \\
\hline Dry mouth & 1 & 0.3 & & & \\
\hline
\end{tabular}

$\mathrm{N}$ - number of patients. 
Focusing on the dental aspect (and counting only people who first consulted a dentist), it was found that patients reported to the dentist because of the first symptom noticed $(\mathrm{N}=52 ; 51.5 \%)$, which was most often ulceration $(\mathrm{N}=12 ; 23 \%)$, induration $(\mathrm{N}=8 ; 15.4 \%)$, an undefined lesion $(\mathrm{N}=7 ; 13.5 \%)$, pain $(\mathrm{N}=5 ; 9.6 \%)$, or a white or grey spot $(\mathrm{N}=5 ; 9.6 \%)$. Other causes that prompted patients to report to a dentist were enlargement of a lesion, a lack of healing or improvement after initial treatment, the onset of pain, intensification of existing symptoms, and in individual cases suppuration, prosthesis mismatch, dysphagia, impaired tongue movement, and a burning sensation in the mouth.

It is noteworthy that in 9 cases (8.9\%), patients noticed nothing disturbing and detection (by the healthcare professional) was accidental. Lesions were detected in 3 patients (3\%) during a medical visit for a different reason (in 2 patients during oncological monitoring for another cancer and in 1 during a visit to an endocrinologist).

\section{Reasons for delay}

This study also includes the most common reasons for delays in the implementation of appropriate treatment. In 125 cases (41\%), the patient caused the delay; in 76 cases (25\%) the healthcare professionals were the cause; and in 32
Table 6. Patients' reasons for delaying

\begin{tabular}{|l|c|c|}
\hline \multicolumn{1}{|c|}{ Patients' reasons for delaying } & N & $\%$ \\
\hline No reason & 148 & 48.5 \\
\hline $\begin{array}{l}\text { Minor symptoms/not significantly impeding } \\
\text { functionality }\end{array}$ & 110 & 36.1 \\
\hline $\begin{array}{l}\text { Home remedies - ointments, pills, rinses, herbs, } \\
\text { self-extraction }\end{array}$ & 19 & 6.2 \\
\hline $\begin{array}{l}\text { Did not apply for treatment/monitoring } \\
\text { Linking symptoms to dentition/denture problem }\end{array}$ & 10 & 4.6 \\
\hline The patient did not notice $\rightarrow$ accidental detection & 9 & 3 \\
\hline
\end{tabular}

$\mathrm{N}$ - number of patients.

cases $(10.5 \%)$ causes of delay lay on both sides. In 72 patients (23.6\%), there was no definitive delaying cause.

Regarding the patients, the most common reason for a delay was that the symptoms of the disease were minor $(\mathrm{N}=110 ; 36.1 \%)$ and did not impair their functionality (Table 6). The reason for delays independent of the patient was usually the initial treatment recommended by the doctors $(\mathrm{N}=108 ; 35.4 \%)$ who sometimes carried it out for a long time, often without monitoring its effectiveness (Tables 7 and 8). Maxillofacial surgeons were less likely than GPs to refer patients to another doctor; and dentists took bioptic samples more often than GPs (Fig. 3).

Table 7. Initial responses by specialization

\begin{tabular}{|c|c|c|c|c|c|c|c|}
\hline Initial medical action & $\begin{array}{l}\text { General practi- } \\
\text { tioner [\%] }\end{array}$ & $\begin{array}{l}\text { Laryngolo- } \\
\text { gist [\%] }\end{array}$ & Dentist [\%] & $\begin{array}{l}\text { Dermatolo- } \\
\text { gist [\%] }\end{array}$ & $\begin{array}{l}\text { Oncologist } \\
{[\%]}\end{array}$ & $\begin{array}{l}\text { Endocrinolo- } \\
\text { gist [\%] }\end{array}$ & $\begin{array}{l}\text { Oromaxillofacial } \\
\text { surgeon [\%] }\end{array}$ \\
\hline $\begin{array}{l}\text { Referral to the ward/other } \\
\text { doctor }(\mathrm{N}=137 ; 44.9 \%)\end{array}$ & 43.8 & 12.4 & 39.4 & - & 2.9 & 0.7 & 0.7 \\
\hline $\begin{array}{l}\text { Bioptic sample taking } \\
(\mathrm{N}=74 ; 24.3 \%)\end{array}$ & 1.4 & 23 & 13.5 & - & - & - & 62.1 \\
\hline Antibiotics ( $\mathrm{N}=29 ; 9.5 \%)$ & 72.4 & 6.9 & 20.7 & - & - & - & - \\
\hline $\begin{array}{l}\text { Gels, ointments, creams } \\
(\mathrm{N}=23 ; 7.5 \%)\end{array}$ & 47.8 & 4.3 & 47.8 & - & - & - & - \\
\hline $\begin{array}{l}\text { Other pharmacotherapy } \\
(\mathrm{N}=18 ; 5.9 \%)\end{array}$ & 72.2 & 22.2 & 5.6 & - & - & - & - \\
\hline Extractions ( $\mathrm{N}=8 ; 2.6 \%)$ & - & - & 100 & - & - & - & - \\
\hline $\begin{array}{l}\text { Antifungal treatment } \\
(\mathrm{N}=7 ; 2.3 \%)\end{array}$ & 28.6 & 28.6 & 42.9 & - & - & - & - \\
\hline Mouth rinses $(\mathrm{N}=6 ; 2 \%)$ & 66.7 & - & 33.3 & - & - & - & - \\
\hline $\begin{array}{l}\text { Endodontic treatment } \\
(\mathrm{N}=4 ; 1.3 \%)\end{array}$ & - & - & 100 & - & - & - & - \\
\hline Curettage $(\mathrm{N}=3 ; 1 \%)$ & - & - & 100 & - & - & - & - \\
\hline $\begin{array}{l}\text { Other ad hoc treatment } \\
(\mathrm{N}=3 ; 1 \%)\end{array}$ & - & 33.3 & 66.6 & - & - & - & - \\
\hline Painkillers ( $N=2 ; 0.7 \%)$ & 50 & 50 & - & - & - & - & - \\
\hline $\begin{array}{l}\text { Prosthetic corrections } \\
(\mathrm{N}=2 ; 0.7 \%)\end{array}$ & - & - & 100 & - & - & - & - \\
\hline $\begin{array}{l}\text { Periodontology treatment } \\
(\mathrm{N}=2 ; 0.7 \%)\end{array}$ & - & - & 100 & - & - & - & - \\
\hline Sore throat pills ( $N=1 ; 0.3 \%)$ & 100 & - & - & - & - & - & - \\
\hline $\begin{array}{l}\text { Laser removal of lesion } \\
(\mathrm{N}=1 ; 0.3 \%)\end{array}$ & - & - & 100 & - & - & - & - \\
\hline
\end{tabular}

$\mathrm{N}$ - number of patients. 
Pearson's $\chi^{2}$ test

$\chi^{2}=46.2 ; \quad \mathrm{df}=3 ; \mathrm{p}<0.001$
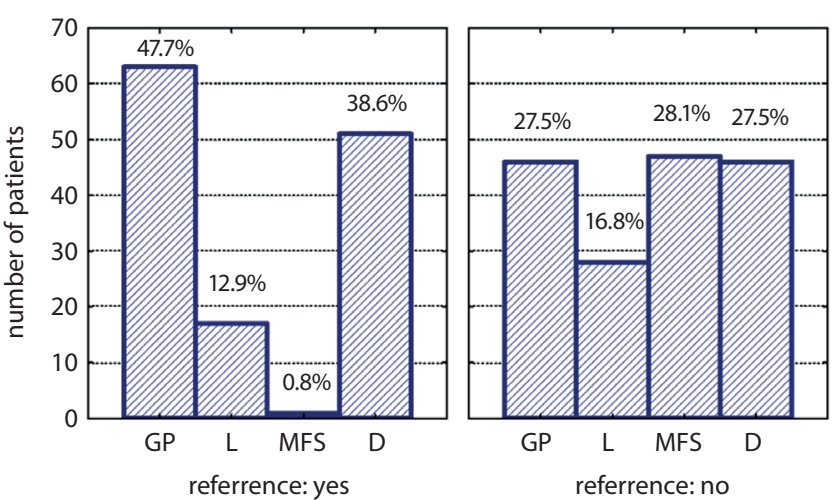

Pearson's $\chi^{2}$ test

$\chi^{2}=187.8 ; \quad d f=3 ; p<0.001$
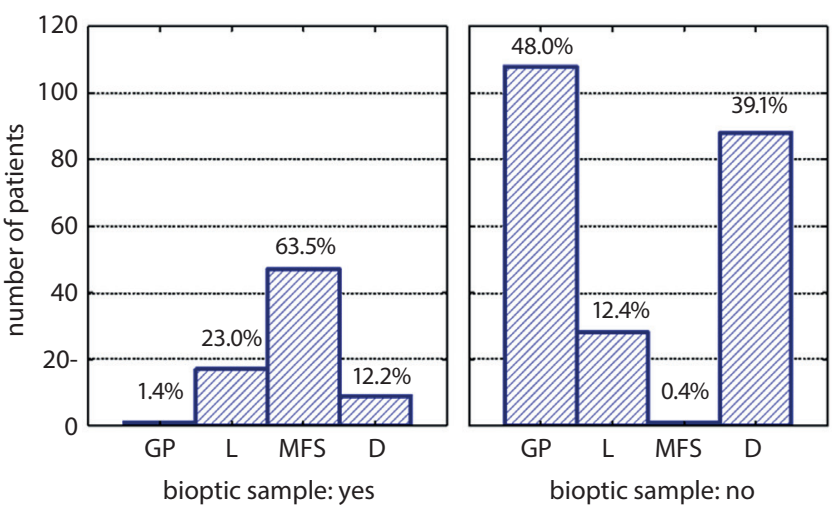

Fig. 3. The number of patients grouped according to primary care and the type of first treatment implemented (referral and bioptic sample retrieval) and the results of the test of independence

GP - general practitioner; L - laryngologist; MFS - maxillofacial surgeon; D - dentist.

Analyzing the individual delays caused by healthcare providers, the most common cause was antibiotic therapy $(\mathrm{N}=33 ; 10.8 \%)$, often repeated and prolonged, ointments and mouth rinses $(\mathrm{N}=27 ; 8.9 \%)$ or other pharmacotherapy $(\mathrm{N}=24 ; 7.9 \%)$ aimed at treating suspected other diseases, such as pharyngitis or aphthous stomatitis, often without monitoring the effectiveness of the treatment. An additional difficulty that increased the possibility of misdiagnosis regarding the oral cavity were symptoms of comorbid inflammation present along with cancer. Other noteworthy problems were incorrect bioptic sample retrieval, long waiting time for appointments or examinations, and above all a lack of oncological awareness on the doctors' part, leading to downplaying the disease and not undertaking further treatment, not retrieving a bioptic sample or even not referring the patient to another specialist (Table 7).

There was no correlation between the type of specialist first visited by the patient and the delay cause $(\mathrm{p}>0.05)$, but when analyzing the role of dentists, it was relatively common to implement dental treatment without determining
Table 8. Professionals' reasons for delay

\begin{tabular}{|l|c|c|}
\hline \multicolumn{1}{|c|}{ Professionals' reasons for delay } & N & $\%$ \\
\hline No reason & 197 & 64.6 \\
\hline Antibiotics & 33 & 10.8 \\
\hline Gels, ointments, rinses - treatment of aphta, ulcers & 27 & 8.9 \\
\hline Other pharmacotherapy & 24 & 7.9 \\
\hline Surgical procedures - extractions/resections & 10 & 3.3 \\
\hline Antifungal treatment & 7 & 2.3 \\
\hline $\begin{array}{l}\text { Incorrect taking of the bioptic sample } \rightarrow \text { incorrect } \\
\text { result/wrong sending of the sample/result not }\end{array}$ & 7 & 2.3 \\
\hline corresponding to the clinical state & & \\
\hline Incorrect diagnosis and no further treatment, & 7 & 2.3 \\
\hline referral, sample taking & & 2 \\
\hline Numerous examinations that extended the diagnosis & 6 & 1.3 \\
\hline Periodontology treatment & 4 & 1 \\
\hline Long wait for visits & 3 & 1 \\
\hline Prosthesis correction or removal & 3 & 0.3 \\
\hline Long wait for histopathology result & 1 & 0.3 \\
\hline Photodynamic therapy & 1 & 1 \\
\hline Repeated patient referral & & 2 \\
\hline
\end{tabular}

$\mathrm{N}$ - number of patients

the real cause of the discomfort. A disturbing fact were the frequently lengthy delays between getting a pathological result from a bioptic sample and implementing appropriate therapy. Often, the time was as long as 2-4 months.

\section{Discussion}

The percentage of patients in the early (I-II: $26.5 \%$ ) and late (III-IV: $73.5 \%$ ) stages of advancement in the group of patients analyzed are comparable to data from other studies, in which patients at advanced stages accounted for $71.4 \%$ of all cases. ${ }^{11}$ On the other hand, in another analysis, the group of patients in the early stages dominated, with $68 \%$ at stages I-II. ${ }^{6}$

The number of doctors consulted by the patient influences the time that passes before the implementation of appropriate treatment. There was a weak positive correlation between the delay time and the number of doctors consulted before a patient's admission to the ward $(\mathrm{p}<0.05)$. This confirms that numerous medical consultations extend the total time before the start of appropriate therapy. Patients most often visited healthcare professionals once (43.2\%) or twice (28.8\%) before they underwent appropriate treatment. This is relatively lower than reported in other studies, where about $60 \%$ of patients visited doctors 3-4 times before obtaining a final diagnosis. ${ }^{11}$ Moreover, prolonged waiting times negatively affect patient's quality of life, which is connected with psychological distress. ${ }^{12}$ In our study, a dentist was often the first healthcare professional consulted for oral cancer 
(31.8\%), which is comparable to Wang et al., who reported that a dentist was one of the specialists in $35 \%$ of the cases. ${ }^{6}$ It is important that sometimes the symptoms that patients report to the dentist, like toothache or discomfort related to a denture, raise suspicions of other potentially trivial ailments, common in dental practice, and may lead to misdiagnosis. The real cause should always be established before any treatment, not forgetting about the possibility of cancer.

Many studies categorize the reasons for delays into those dependent on the patients and those dependent on healthcare professionals. This study considers the entire delay time, from the moment of noticing the first symptom until the patients' admission to the Department of Maxillofacial Surgery. The average was $7.4 \pm 13.9$ months (slightly over 200 days), which is similar to a study by Peacock et al., where the overall mean delay was 203.8 days. Those authors concluded this delay is unacceptable. ${ }^{13}$ Some authors count the time of delay separately for the patients and specialists, and they emphasize that there is no consensus about a time point beyond which a diagnosis could be considered delayed. ${ }^{14}$ The definition of professional delay is the period from the patient's first consultation with a healthcare professional up to the final pathological diagnosis. One of the reasons for professional delay is inadequate clinical examination, but also nonspecific clinical symptoms, a low index of suspicion, a lack of familiarity and experience with the disease, and comorbidity. ${ }^{7}$ In a study by Esmaelbeigi et al., ${ }^{11}$ the total time was 140 days. As many as 45 days depended on the patient and 86 days on the doctors. Others emphasize the patients' delays, considering them to be the main delaying component, because the duration was over 3 months in $48 \%$ of cases. ${ }^{6}$ In our study, the patients caused delays in $41 \%$ of the cases, the doctors in $40.55 \%$ and both in $10.5 \%$. Sometimes, however, even $80 \%$ of reasons for delay are attributed to patients due to the fact that despite noticing a disturbing lesion, $30 \%$ of patients wait over 3 months until they see a doctor. ${ }^{10}$

Public awareness of oral cancer seems alarmingly low, as Warnakulasuriya et al. reported. ${ }^{15}$ Patients are unaware of the etiology of their symptoms and often downplay the first signs even when they are long-lasting. In 1 study, only $13 \%$ of the patients thought their symptoms were caused by a potentially serious reason, while $50 \%$ of them believed it would get better by itself. ${ }^{16}$ The reason is usually that the early symptoms do not affect functionality to a large extent. Patients also often undertake independent home treatment, even without consulting a doctor. Patients who took traditional herbal medication before seeking professional help had significant delays in the diagnosis of cancer. ${ }^{16}$ Earlier detection is possible in cases where the patient is concerned about severe symptoms such as painful ulceration or bleeding. ${ }^{8}$

Previously existing symptoms - sore throat, cough or hoarseness because of addictions - may also mask the appearance of the first symptoms of head and neck cancer in patients abusing tobacco and alcohol. ${ }^{9}$ Unfortunately, doctors often prescribe medications (especially painkillers) to reduce symptoms they perceive as minor. Sometimes they carry out dental treatment that is also only symptomatic. When it comes to dentists, it is noteworthy that a loss of teeth by the patient increases the risk of delay by as much as 4 times. Prior conservative, surgical or periodontal treatment significantly prolongs delays and contributes to the deterioration of the existing condition. The risk of professional delay in such cases increases over 7 times. ${ }^{11}$ The symptoms that patients report to their primary care doctors are often suggestive of viral infection or tonsillitis, such as a sore throat or enlarged lymph nodes of the neck. This prompts the doctor to prescribe antibiotic therapy instead of looking for the real cause. ${ }^{8}$ This confirms that health professionals' oncological awareness is important, even though the patients' role in delaying the implementation of appropriate treatment is significant.

In the present study, the most frequently reported symptom was an undetermined lesion (23.3\%), as Goy et al. also reported. ${ }^{9}$ In contrast, ulceration is the most frequent clinical observation (53.9\%), which has been confirmed by data from other authors. ${ }^{16}$ Two critical signs present in almost all cancers are induration and fixation. Oral squamous cell carcinomas (OSCCs) present either as a red or white patch, an endophytic ulcerative lesion, or a more exophytic mass with rolled margins, central ulceration and tissue friability. ${ }^{7}$ Lesions of this type should immediately be subjected to further verification.

Reducing the duration of delays is essential, although there was no significant relationship between delay and tumor advancement in our study. Other authors emphasize that patients diagnosed with a certain delay have a 3 times greater risk of a diagnosis of cancer at a more advanced stage than patients diagnosed without delay. ${ }^{11}$ Long-term survival also depends on tumor advancement. During a long-term analysis, $51.3 \%$ of the late-stage patients died, as opposed to $28.1 \%$ at an early stage. ${ }^{6}$ Some say, however, that the tumor advancement at diagnosis is mainly determined by the rate of its growth, and with rapid growth this time is shorter and the advancement is higher; and vice versa with slowly growing tumors. ${ }^{4,6,17}$ That sometimes explains a lack of relationship between delay and advancement, ${ }^{17}$ just as in our study, where there was no such correlation or dependence between the time and the number of additional symptoms related to a tumor. Tumors of the head and neck region are characterized by relatively rapid proliferation, so the period of early detection is shorter. ${ }^{4}$ With considerable advancement and because of many intensified symptoms, there is a lower risk of missing the tumor and the delay time is shorter. ${ }^{17}$ The stronger link between delay and tumor advancement in oral cancer compared to throat cancer reported by some authors is probably because throat cancer metastasizes at earlier stages. ${ }^{14}$ 
Both our analysis and conclusions from the literature draw attention to the level of oncological awareness, as the most common "professional" causes of delay include neglecting to consider cancer in the differential diagnosis and prescribing other treatment. ${ }^{11}$ It is also necessary to pay attention to pre-cancerous lesions and their continuous monitoring. ${ }^{6,14}$ In our study, the location of the tumor has no significant relationship with the possibility of observing symptoms, which underlines the crucial role of accurate diagnosis by the first healthcare professional consulted. Differential diagnoses including cancer should also be performed among younger patients (under 45 years of age), because a common cause of overlooking cancer is a lack of suspicion because of a patient's young age. ${ }^{14}$

Due to the fact that the only source of data was the patients' anamnesis, there was a risk of unreliable results. However, our results are similar to the data found in other studies, as has been shown above. Another prospective study specifically considering monitoring treatment effectiveness could be performed in the future to further explore the problem.

\section{Conclusions}

The present study confirms the need to improve the level of oncological awareness in society, especially among healthcare professionals (GPs and dentists). Mandatory educational programs for doctors (as well as for medical students), focused primarily on in-depth interviews and clinical examinations, would help reduce the delay and shorten the diagnostic process. It is also essential to inform patients about maxillofacial oncology (attention to first symptoms, self-monitoring), especially those in high-risk groups, both during dental visits and social campaigns. Early detection of cancer may contribute to implementing appropriate treatment at low stages of advancement. Less invasive surgery is undoubtedly associated with a quicker, less demanding convalescence and a higher quality of life after surgery. Because of the necessity to exclude a relatively large group of patients due to the lack of all the required data for the study, it is necessary to create a full medical interview scheme, taking into account all the necessary data for further research.

\section{ORCID iDs}

Monika Rutkowska (D) https://orcid.org/0000-0003-0243-7751 Sylwia Hnitecka (1) https://orcid.org/0000-0002-1171-9817 Marek Nahajowski (D) https://orcid.org/0000-0003-4679-5649 Marzena Dominiak (D https://orcid.org/0000-0001-8943-0549 Hanna Gerber (D) https://orcid.org/0000-0002-0954-3955

\section{References}

1. World Health Organization. Global Health Observatory. Geneva, Switzerland: World Health Organization; 2018. who.int/gho/database/en/. Accessed June 21, 2018.

2. Lingen MW, Kalmar JR, Karrison T, Speight PM. Critical evaluation of diagnostic aids for the detection of oral cancer. Oral Oncol. 2008;44(1):10-22.

3. Chang TS, Chang CM, Ho HC, et al. Impact of young age on the prognosis for oral cancer: A population-based study in Taiwan. PLoS One. 2013;8(9):75855.

4. van der Waal I. Are we able to reduce the mortality and morbidity of oral cancer: Some considerations. Med Oral Patol Oral Cir Bucal. 2013;18(1):33-37.

5. Carvalho AL, Nishimoto IN, Califano JA, Kowalski LP. Trends in incidence and prognosis for head and neck cancer in the United States: A site-specific analysis of the SEER database. Int J Cancer. 2005;114(5):806-816.

6. Wang $\mathrm{KH}$, Song $\mathrm{BH}$, Gilde JE, et al. Diagnostic pathway of oral cavity cancer in an integrated health care system. Perm J. 2018;22:17-152.

7. Baykul T, Yilmaz HH, Aydin U, Aydin MA, Aksoy M, Yildirim D. Early diagnosis of oral cancer. J Int Med Res. 2010;38(3):737-749.

8. Pitchers $M$, Martin C. Delay in referral of oropharyngeal squamous cell carcinoma to secondary care correlates with a more advanced stage at presentation, and is associated with poorer survival. Br J Cancer. 2006;94(7):955-958.

9. Goy J, Hall SF, Feldman-Stewart D, Groome PA. Diagnostic delay and disease stage in head and neck cancer: A systematic review. Laryngoscope. 2009;119(5):889-898.

10. McGurk M, Scott SE. The reality of identifying early oral cancer in the general dental practice. Br Dent J. 2010;208(8):347-351.

11. Esmaelbeigi F, Hadji M, Harirchi I, Omranipour R, vand Rajabpour M, Zendehdel K. Factors affecting professional delay in diagnosis and treatment of oral cancer in Iran. Arch Iran Med. 2014;17(4):253-257.

12. Gigliotti J, Madathil S, Makhoul N. Delays in oral cavity cancer. Int J Oral Maxillofac Surg. 2019;48(9):1131-1137.

13. Peacock ZS, Pogrel MA, Schmidt BL. Exploring the reasons for delay in treatment of oral cancer. J Am Dent Assoc. 2008;139(10):1346-1352.

14. Gómez I, Seoane J, Varela-Centelles P, Diz P, Takkouche B. Is diagnostic delay related to advanced-stage oral cancer? A meta-analysis. Eur J Oral Sci. 2009;117(5):541-546.

15. Warnakulasuriya KA, Harris CK, Scarrott DM, et al. An alarming lack of public awareness towards oral cancer. Br Dent J. 1999;187(6): 319-322.

16. Güneri P, Epstein JB. Late stage diagnosis of oral cancer: Components and possible solutions. Oral Oncol. 2014;50(12):1131-1136.

17. Seoane-Romero JM, Vázquez-Mahía I, Seoane J, Varela-Centelles $P$, Tomás I, López-Cedrún J-L. Factors related to late stage diagnosis of oral squamous cell carcinoma. Med Oral Patol Oral Cir Bucal. 2012;17(1):35-40. 